\title{
BMJ Open Smoking prevention in adolescents: a cross-sectional and qualitative evaluation of a newly implemented prevention program in Switzerland
}

\author{
Andrea Meienberg (D) , ${ }^{1}$ Michael Mayr (D) , ${ }^{1}$ Annina Vischer, ${ }^{1}$ Michael J Zellweger, ${ }^{2}$ \\ Thilo Burkard ${ }^{1,2}$
}

To cite: Meienberg A, Mayr M, Vischer A, et al. Smoking prevention in adolescents: a cross-sectional and qualitative evaluation of a newly implemented prevention program in Switzerland. BMJ Open 2021;11:e048319. doi:10.1136/ bmjopen-2020-048319

- Prepublication history and additional supplemental material for this paper are available online. To view these files, please visit the journal online (http://dx.doi.org/10.1136/ bmjopen-2020-048319).

Received 24 December 2020 Accepted 09 November 2021

D Check for updates

(c) Author(s) (or their employer(s)) 2021. Re-use permitted under CC BY-NC. No commercial re-use. See rights and permissions. Published by BMJ.

${ }^{1}$ Medical Outpatient Department, University Hospital Basel and University of Basel, Basel,

Switzerland

${ }^{2}$ Department of Cardiology, University Hospital Basel and University of Basel, Basel,

Switzerland

Correspondence to

Dr Andrea Meienberg;

andrea.meienberg@usb.ch

\section{ABSTRACT}

Objectives In 2014, a hospital-based smoking prevention programme 'Nichtrauchen ist clever!' (NIC!) for adolescents aged 12-14 was initiated. The aim of the study was to evaluate participants' smoking behaviour and to explore the acceptance of the programme, and participants' awareness on smoking-related diseases and factors that promote smoking initiation.

Design We performed a cross-sectional survey to evaluate participant's acceptance of the NIC! program and their smoking habits. A total of 1658 participants completed the survey between January 2016 and December 2019. A qualitative approach, including analysing feedback from students gathered at 77 prevention events between June 2014 and December 2019, was used to assess their view on reasons for smoking initiation and their knowledge about smokingrelated diseases.

Results Twenty-six per cent (429/1658) have already tried tobacco products (so called triers), specifically cigarettes, electronic (e)-cigarettes and shisha. The use of e-cigarettes was most popular among triers $58 \%(252 / 429)$. Eighty-eight per cent of participants (1408/1604) reported they had acquired good or excellent knowledge about smoking, and 89\% (1439/1617) of participants stated that they intend not to smoke in the future. Particularly lung cancer and cancer in general, heart-and vascular diseases were frequently mentioned to be smoking related; where, on the other hand, a large number of relevant smoking-associated diseases were mentioned irregularly. Peer pressure, stress and coolness were identified as reasons for smoking initiation, whereas the influence of marketing and multimedia, as well as socioeconomic - and lifestyle-related factors on smoking behaviour was barely noticed.

Conclusion NIC! had a high acceptance among the participants and a large number of students reported relevant gain of knowledge. We identified important knowledge-gaps relating to smoking initiation and smoking-related diseases, helping to improve further smoking prevention approaches.

\section{INTRODUCTION}

Smoking is one of the most important risk factors for morbidity relating to various
Strengths and limitations of this study

- The most important methodological limitation is the observational cross-sectional approach of the study.

- The study design and methodology do not allow any conclusion on programme effectiveness in smoking prevention.

- The data rely on a self-reported questionnaire, which carries the risk of reporting bias.

- The study participants visited different schools and different proficiency levels in an urban area and the adjacent rural region in one of the largest cities in Switzerland, which is why the study has a certain representative character in comparable European regions.

- With a pragmatic approach of an easy feedback survey design, we were able to achieve a high response rate, with $83 \%$ of the participants.

organ systems. ${ }^{1}{ }^{2}$ Furthermore, tobacco consumption is an important preventable cause of premature death worldwide. ${ }^{34}$ On average, smokers die 10 years earlier than non-smokers. ${ }^{5}$

Nevertheless, smoking is still common, globally as well as in Switzerland. ${ }^{6} 7$ The overall prevalence in Switzerland is approximately $25 \%$ in adults. ${ }^{7}$ Smoking in adulthood is closely associated with smoking during adolescence. ${ }^{178}$ According to a 2014 survey on smoking habits in children and adolescents in Switzerland, the first contact with cigarettes occurred around the age of 13 years. ${ }^{9}$ Recently, alternative forms of tobacco products have gained popularity among young adults; especially the use of shishas and e-cigarettes. ${ }^{10}{ }^{11}$ Nicotine is a highly addictive substance and, compared with adults, one assumes that children/adolescents are at even greater risk of rapidly developing a nicotine addiction. ${ }^{12}{ }^{13}$ Consequently, occasional smoking or even experimenting with 
tobacco products at a vulnerable age can quickly escalate into heavy smoking. ${ }^{714}$ Therefore, as a global epidemic, tobacco consumption must not only be tackled in adults, but it is particularly important to focus on smoking prevention among young people.

With this background in mind, we have introduced an in-hospital, physician-led smoking prevention programme for schoolchildren aged 12-14 years called 'Nichtrauchen ist clever! (NIC!)' at the University Hospital Basel. The programme was oriented on the programme 'ohnekippe', conducted in Heidelberg, ${ }^{15}$ and adapted to local circumstances. Further information about the regional introduction of NIC! and the core components of the programme are provided in the online supplemental file 1 . In brief, NIC! consists of an interactive workshop, a video presentation of a medical examination and a patient interview by physicians and students. NIC! was first introduced in June 2014 with a pilot phase, collection of standardised feedback started in 2016.

The aim of the present analysis was to evaluate the acceptance of the programme, to assess the smoking habits of the students and their self-reported knowledge gain. Furthermore, we explored students' awareness on smoking-related diseases and factors that promote smoking initiation. This assessment is to help future interventions using a similar approach.

\section{METHODS}

\section{Study design and population}

NIC! was offered to school classes at the target age group in the area of Basel, the third largest city in Switzerland, and the surrounding rural area. Participating school classes came from different educational levels. Each event consisted of 1-3 school classes, with a total number of participants of approximately 25-50 adolescents per event.

The present study consists of two parts: a cross-sectional survey and a qualitative design with a content analysis.

\section{Data collection}

Cross-sectional postparticipation survey

All students participating in a NIC! event from January 2016 to December 2019 were included in the analysis. A cross-sectional design with a written survey was chosen to assess the acceptance of the different parts of the programme, and student's gain of knowledge, using a four-point Likert scale with emoji's, ranging from $\odot$ to

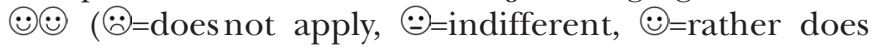
apply; $(:) \cdot=$ does apply strongly), used as categories. Furthermore, we assessed demographic data (age and sex), and smoking habits, specifically for traditional cigarettes, e-cigarettes and shishas. Moreover, we have recorded their future smoking intention.

Teachers were informed about the programme evaluation when visiting 'NIC!' and the surveys for each participating school class were provided to the teacher (online supplemental file 2). One week following participation, the teachers informed the students about the evaluation and distributed, collected and returned all questionnaires. Participation was voluntary for teachers and students and data collection was completely anonymous.

\section{Content analysis on awareness}

We evaluated the students' awareness on smoking related diseases and factors that promote smoking initiation using content analysis with a deductive coding frame, according to the step model of deductive category application. ${ }^{16}$ Qualitative data collection was itself part of the programme and took place during the 45-min interactive workshop of each prevention event. We included all workshops from June 2014 to December 2019 in our content analysis.

Specifically, we discussed the following two questions with the participants:

- Let us discuss the topic of smoking initiation: Why do you think young people start smoking?

- Let us go into more detail about the potential harms and health consequences of smoking. What do you know about it? What kind of smoking-related diseases are you familiar with?

Students were motivated to provide answers and discuss the topic within the workshop. Answers and discussion points mainly as keywords were visibly listed on an overhead projector during the prevention event. Discussion about the topic and data collection within the workshops was closed, when saturation was noticeable. All data were then transferred to a chart. $\mathrm{AM}$ and $\mathrm{TB}$, member of the study team, discussed the data, developed the codes and overarching categories and allocated the codes to the categories. Besides identifying participants' awareness on well-known reasons for smoking initiation, we intended to uncover possible knowledge gaps or to identify possible trends among participants.

\section{Data analysis and statistics}

\section{Cross-sectional postparticipation survey}

We used descriptive statistics for the quantitative analysis of the educational outcome. Categorical variables were expressed as counts (percentage). Continuous variables were expressed as mean $\pm \mathrm{SD}$ if normally distributed, or as median and IQR if not normally distributed. Continous data were compared using a Mann-Whitney $\mathrm{U}$ test after visual analysis of the data distribution. Categorical data were analysed using a Fisher's exact test. All statistical analyses were performed using SPSS V.22 (SPSS) and R V.3.6.0. ${ }^{17} \mathrm{P}<0.05$ were regarded statistically significant.

Definitions: all students who stated they had tried a tobacco product at least once (lifetime prevalence) andin accordance with the literature-students with missing values on their tobacco use were counted as 'triers', ${ }^{18} 19$ assuming that the participants would rather leave the field blank than admit they smoked (under-reporting). 


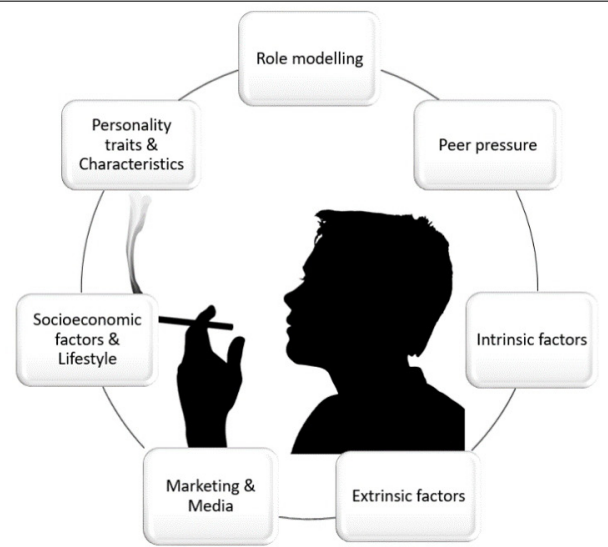

Figure 1 Seven predefined categories on factors promoting smoking initiation in the young, used for the content analysis. Bildquelle: Shutterstock.com/Snap2Art.

Content analysis on awareness

Students' perception on factors influencing smoking initiationsteps of data analysis

Based on a thorough review of the literature, we identified several factors that were predictive of smoking initiation, ${ }^{420-24}$ whereof we predefined and formulated seven different categories of factors that influence smoking initiation in adolescence (figure 1):

1. Role modelling.

2. Peer pressure.

3. Intrinsic factors: for example - reduction of stress symptoms, depression, overweight/worrying about one's weight.

4. Extrinsic factors: for example - image and coolness.

5. Marketing \& Media.

6. Socioeconomic factors and lifestyle-related indicators: for example - alcohol consumption, low school performance, use of other tobacco products.

7. Personality traits \& Temperamental characteristics: for example - sensation seeking, risk-taking propensity, impulsivity.

After definition of categories and coding rules, we familiarised ourselves with the answers of the students in a reading and rereading process. Then, we transformed students' answers into meaningful codes. Deductively, the various codes were assigned to the predefined and matching categories when possible. Codes not matching any of the predefined categories were allocated to 'others'.

We completed analysis, with a final quantification of the codes across the different categories and across all events; specifically, each coded category got one count per event.

\section{Students' knowledge on smoking-related diseases-steps of data analysis}

Before we were able to analyse students' answers on their understanding/knowledge about smoking-related diseases, we had to agree on a current level of evidence on diseases associated with smoking. We therefore defined the infographic of the Center for Disease Control and Prevention (CDC) as our standard level of evidence when we started the prevention programme in 2014 (see online supplemental file). ${ }^{25}$ The infographic divides smokingrelated diseases in two groups, namely cancer and chronic diseases. The diseases listed in the infographic were selected as our predefined categories on smoking related diseases ( 15 cancers and 23 chronic diseases). The process of data analysis was done in analogy to 'Students' perception on factors influencing smoking initiation'.

\section{Patient and public involvement}

The principal of a pilot school was involved in the conceptualisation of the prevention programme NIC!, the local health and educational authorities in the distribution of the prevention programme. Direct feedback on the event by the teachers and participants was obtained during a joint meal directly after the events. During these joint meals, adolescents had the possibility for further questions.

\section{RESULTS}

\section{Cross-sectional postparticipation survey}

\section{Population and tobacco use}

Between January 2016 and December 2019, 55 NIC! events with about 1995 students were held at the University Hospital Basel. The number of participants was deduced from the number of participants registered for the events. Overall, 1658 students returned the survey and were included in the analysis, accounting for a response rate of $83 \%(1658 / 1995)$. Table 1 summarises characteristics of the participants. Their mean age was $13.3(\mathrm{SD} \pm 0.9)$ years. Twenty-six per cent $(429 / 1658)$ of participants have already tried tobacco products at least once (=triers). Lifetime prevalence of e-cigarette use among study participants was $15 \%(252 / 1658)$, conventional cigarettes $12.5 \%(207 / 1658)$ and shisha $12 \%$ $(197 / 1658)$. Ten per cent $(43 / 429)$ of triers reported to smoke regularly. Focussing on regular smokers, conventional cigarettes $(2 \% ; 32 / 1658)$ were the most commonly used tobacco products, followed by e-cigarettes $(1.5 \%$; $24 / 1658)$ and shisha $(1 \% ; 17 / 1658)$, respectively.

When comparing triers versus non-triers, triers were older (median 14 years (IQR 13-14) vs 13 years (IQR $13-14) \mathrm{p}<0.0005)$, and more often men $(64 \%$ vs $49 \%$, $\mathrm{p}<0.0005)$.

Figure 2 summarises the distribution of the different tobacco products used among triers. E-cigarettes were the products most often tried in 58\% (252/429), followed by conventional cigarettes in $48 \%$ (207/429), and shisha in $46 \%(197 / 429)$ of participants, respectively. However, distribution of the tobacco product used, differed slightly among regular and irregular smokers (figure 2).

\section{Program acceptance and knowledge gain}

The assessment of students' reaction to the three parts of the prevention programme (workshop, film and interview) and participants self-reported knowledge gain are shown in figure 3. Eighty-nine per cent $(1436 / 1614)$ of 
Table 1 Characteristics of the participants of 'Nichtrauchen ist clever!' (NIC!)

\begin{tabular}{|c|c|}
\hline Characteristics & \\
\hline 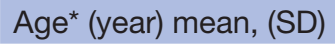 & $13.3( \pm 0.9)$ \\
\hline \multicolumn{2}{|l|}{ Gender†; n, (\%) } \\
\hline Male & $838(53)$ \\
\hline Female & $741(47)$ \\
\hline \multicolumn{2}{|c|}{ Experience with tobacco products $\neq, n=1658 ; n(\%)$} \\
\hline No triers & $1229(74)$ \\
\hline Triers & $429(26)$ \\
\hline
\end{tabular}

Data collection between January 2016 and December 2019 from $55 \mathrm{NIC}$ ! - events. Postparticipation survey was returned by $n=1658$ participants.

${ }^{*}$ Age $\mathrm{n}=1586$

†Gender $\mathrm{n}=1579$.

‡Experience with tobacco products $n=1658$, including missing data from 37 students, which were counted as triers.

the participants rated the workshop, $72 \%$ (1153/1599) the film and $93 \%(1530 / 1640)$ the patient interview as either good or excellent. Overall, $88 \%(1408 / 1604)$ of the participants reported good or excellent knowledge gain.

\section{Future intention of smoking}

After the NIC! event 89\% (1439/1617) of participants stated that they intend not to smoke in the future. Students who were still undecided about their future smoking behaviour differed significantly from students, who were determined not to smoke in the future, with respect to age and previous experiences with tobacco products (table 2). Furthermore, there is a significant difference in their perception regarding knowledge gain as well as their reaction to the programme-based on the analysis of the assessment of the three core components of the prevention event (workshop, film, interview).

In addition to table 2, figure 4 shows a comparison of the participants' self-evaluation of the knowledge gained from the event and the assessments of the three core

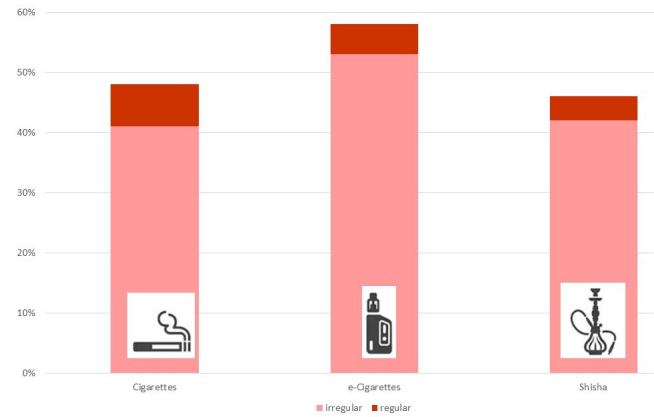

Figure 2 Overview on the different tobacco products used by the 429 students indicating to have tried any kind of tobacco products, namely cigarettes, e-cigarettes and shisha; divided into regular smokers (scarlet) and irregular smokers (light red). Multiple answers were possible. Bildquelle: Shutterstock.com/supanut piyakanont. components of the prevention event, broken down into binary data: 'I intend not to smoke' and 'undecided'.

\section{Content analysis on awareness}

We analysed students' answers on factors that promote smoking initiation and the awareness on smoking related diseases from 70 NIC! workshops.

Students view on factors influencing smoking initiation

Participants of all events were aware of various influences that could lead to the onset of smoking. Through the evaluation of the answers and keywords, 37 codes on factors influencing smoking initiation emerged and were allocated to the seven predefined categories. Table 3 gives an overview of the different codes, their frequency and distribution within the predefined categories. Codes that did not fit to any category were summarised in the category others.

'Peer pressure' $(77 \% ; 54 / 70)$, stress $(76 \% ; 53 / 70)$, represented in the 'intrinsic factors' category and coolness $(76 \% ; 53 / 70)$ as a representative of an 'extrinsic factor', were the three most commonly stated factors (table 3). Examples of quotes, from which these frequently mentioned codes have emerged are 'group identity', 'peer pressure', 'to be part of the group' for peer pressure; 'to much stress', 'to calm down, because you are stressed out', and 'for calming', for stress. 'To be cool', 'to appear cool', 'because it's cool' led to coolness, and 'to feel grown up' to act like an adult. The quotes 'due to depression', and 'because you suffer from depression' led to the coding depression; 'because you have problems', 'when you have problems at home' to problems; 'out of curiosity', 'because you want to try it out', to curiosity; and 'because parents smoke', 'parents as role models' to parents who smoke.

There was no predefined category representing exclusively pleasurable factors for smoking initiation, such as joy or taste. These were occasionally mentioned (pleasure $14 \%(10 / 70)$, fun $6 \%(4 / 70)$, taste $4 \%(3 / 70))$ and subsumed in the category of intrinsic factors.

Factors promoting smoking initiation representing the categories 'Marketing and Media' in 3\% (2/70), as well as 'Socioeconomic factors' and 'Lifestyle-related indicators' in $1 \%(1 / 70)$ " were mentioned in single events.

\section{Students' perception about smoking-related diseases}

Participating students were aware of dangers and risks of smoking. In every interactive workshop, students brought up the addictive nature of nicotine. They were able to recall a variety of diseases and symptoms associated with smoking. Figure 5 gives an overview of student's answers on smoking-related diseases grouped in cancers and chronic diseases, according the CDC infographic, and additional nominations of risks of smoking brought up by the students. Particularly lung cancer in $80 \%$ $(56 / 70)$ and cancer in general 69\% (48/70), followed by heart problems (eg, heart disease and heart attack $66 \%(46 / 70))$ were mentioned. Any kind of chronic 


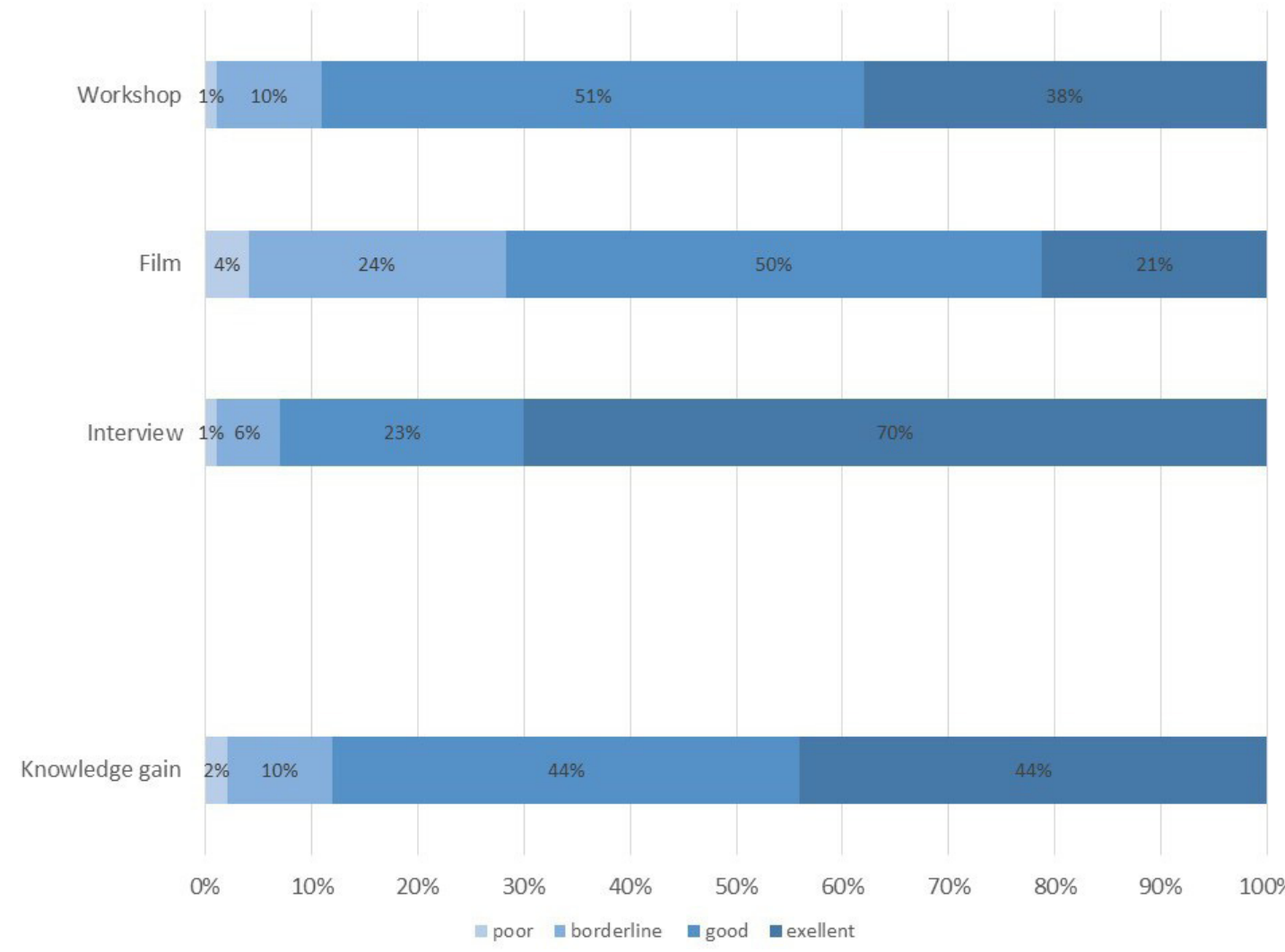

Figure 3 Students ratings to the different core parts of the prevention programme (workshop-film-interview). Measurements

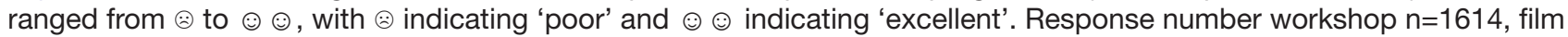
$n=1599$, interview $n=1640$. Data are shown as \%.

lung disease, including asthma and chronic obstructive pulmonary disease were mentioned in half of the events $(35 / 70)$. Non-lethal smoking-related consequences, as the effect on appearance (eg, skin ageing $6 \% ;(6 / 70)$, brittle nails $4 \%(3 / 70)$ and the effect on the physical activity (reduced performance $4 \% ; 3 / 70$ ) were rarely mentioned.

\section{DISCUSSION}

In our study, we present an overview on our physician-led, hospital-based smoking prevention programme Nichtrauchen ist clever! at the University Hospital Basel, Switzerland. We focus on the question how participants value the different parts of the programme and their gain of knowledge, their self-reported experience with tobacco

\begin{tabular}{|c|c|c|c|}
\hline Characteristics & Intention not to smoke & Indifferent & $P$ value \\
\hline Age, median (IQR), n & $13(13-14) n=1382$ & $13(13-14) n=169$ & $p=0.002 \dagger$ \\
\hline Triers, n (\%) & $306 / 1439$ (21.3) & $109 / 178$ (61.2) & $\mathrm{p}<0.0005^{\star}$ \\
\hline $\begin{array}{l}\text { Knowledge gain } 1=\odot, 4=\odot \odot \\
\text { median (IQR), } n\end{array}$ & $3(3-4), n=1399$ & $3(3-3), n=168$ & $\mathrm{p}<0.0005 \dagger$ \\
\hline $\begin{array}{l}\text { Workshop } 1=\odot, 4=\odot ; \\
\text { median }(I Q R), n\end{array}$ & $3(3-4), n=1409$ & $3(2-3), n=169$ & $\mathrm{p}<0.0005 \dagger$ \\
\hline $\begin{array}{l}\text { Film } 1=\odot, 4=\odot \odot \\
\text { median }(I Q R), n\end{array}$ & $3(2-3), n=1392$ & $3(2-3), n=171$ & $\mathrm{p}<0.0005 \dagger$ \\
\hline $\begin{array}{l}\text { Interview } 1=\odot, 4=\odot \odot) \\
\text { median }(\mathrm{IQR}), \mathrm{n}\end{array}$ & $4(3-4), n=1425$ & $4(3-4), n=178$ & $\mathrm{p}=0.001 \dagger$ \\
\hline
\end{tabular}

Comparison of participants according to their intention to smoke. Variables expressed as frequency $n$ (\%), median with IQR (25-75).

${ }^{*}$ Fisher's exact test was used for between-group comparison as appropriate, $p<0.05$ was considered statistically significant.

†Mann-Whitney U test. 

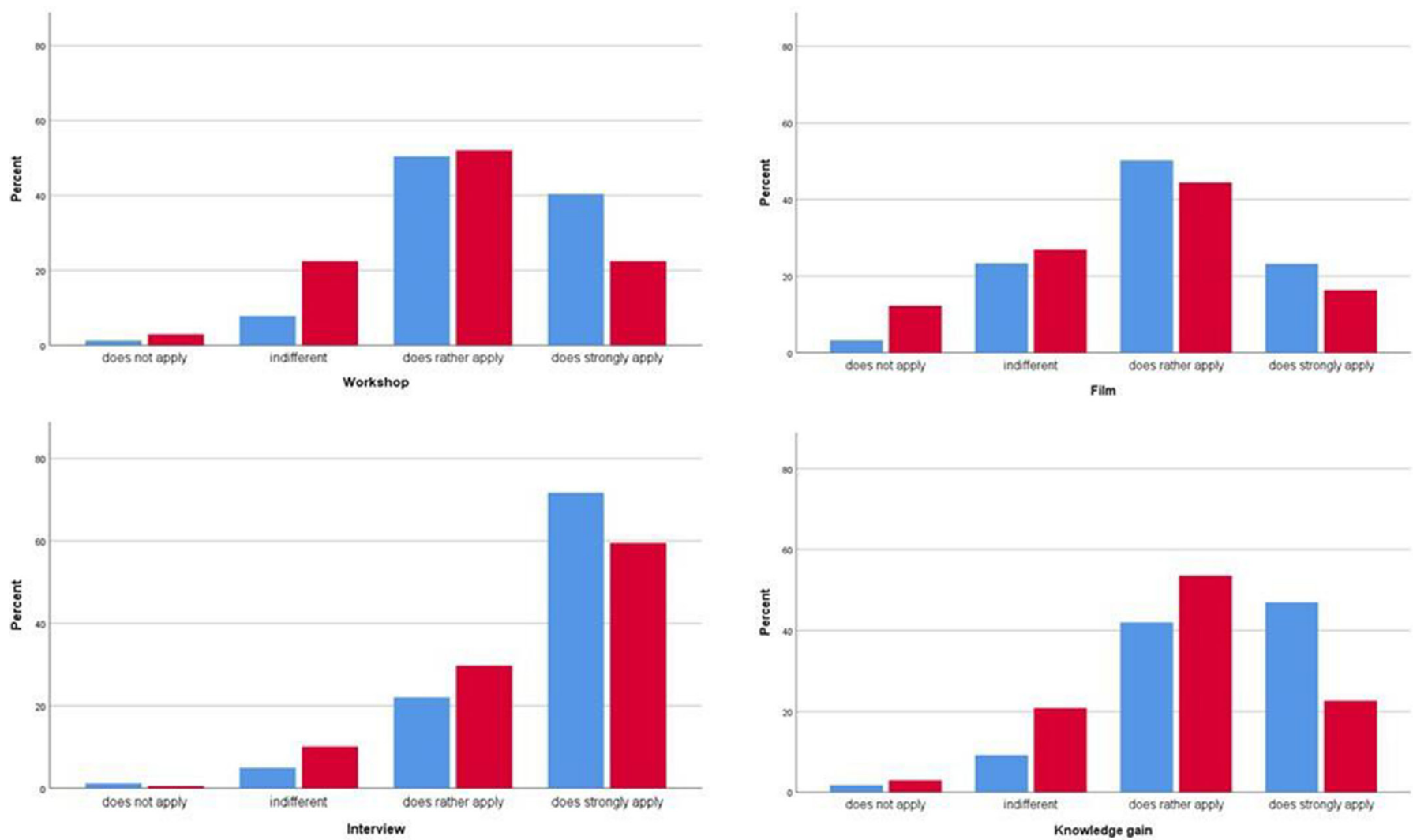

never to smoke

don't know

Figure 4 Comparison of participants' assessments of the three core components of the prevention event 'Nichtrauche ist clever!' (eg, workshop-film-patient interview) and their self-evaluation of the knowledge gained from the event broken down into binary data by the groups: 'I intend not to smoke=never to smoke' and the 'undecided=I don't' know'.

products, as well as their awareness on smoking related health risks and factors that promote smoking initiation.

\section{Population and tobacco use}

In our cohort, $26 \%$ of participants, at a median age of 13 years, reported that they have already tried tobacco products (eg, conventional cigarettes, e-cigarettes, shisha). The proportion of conventional cigarettes use $(12.5 \%)$ was considerably lower in comparison to those seen in a national wide representative survey $(33 \%$ by the age of 13 years) ${ }^{8}$ There are three possible reasons for this observation. First—a selection bias of the study sample—although school classes participating NIC! came from different school sites and different scholaristic abilities, the study sample may not necessarily correspond to a representative cohort of students of Switzerland. Second-a reporting bias-as our data relies on self-reported questionnaires, which in turn might lead to a certain underreporting (social desirability bias). Third, a possible change in behaviour over time, as the national wide survey dated back to 2014 and during the last years large US cohorts witness a shift towards E-cigarette use. ${ }^{26} 27$

Among the triers at baseline, the proportion of students who have already experienced e-cigarettes was markedly higher in comparison to the use of conventional cigarettes. These findings match with the growing evidence of an increased use of alternative forms of smoking, for example, e-cigarettes ${ }^{11}$ and shishas, among adolescents even before trying conventional cigarettes. ${ }^{28}$ This trend is particularly concerning as there is growing evidence of a relevant association between e-cigarette use and subsequent initiation of cigarette smoking, with e-cigarettes serving as a potential door opener for conventional smoking. ${ }^{29-32}$ The high popularity of e-cigarettes in younger adolescents may be due to the fact that young adults perceive the new tobacco products positively, ${ }^{33}$ which encourages them to try them. Furthermore, adolescents are aware of certain harmful effects of conventional cigarettes, as we can see in our data and in a cohort of Chinese adolescents, where $97 \%$ of the study population were aware of lung cancer as a smoking-related disease. ${ }^{34}$ However, currently we do not know much about adolescents' knowledge on health effects of shisha and e-cigarette. Along with a basic curiosity anchored in adolescents, these reasons may overrule the inhibition threshold to try e-cigarettes or shishas. Additionally, the appearance of the new electronic devices (e-cigarettes and e-shishas) in different colours and flavours may make them particularly attractive for younger adolescents. ${ }^{33}$ Furthermore, marketing strategies of tobacco companies also play an important role as they focus on adolescents as their target 
Table 3 Analysis of students answers on factors promoting smoking initiation from 70 Nichtrauchen ist clever! workshops

\begin{tabular}{|c|c|c|c|c|c|c|c|}
\hline \multicolumn{2}{|l|}{ Peer pressure } & \multicolumn{2}{|l|}{ Intrinsic factors } & \multicolumn{2}{|l|}{ Extrinsic factors } & \multicolumn{2}{|c|}{$\begin{array}{l}\text { Socioeconomic factors and } \\
\text { Lifestyle-related indicators }\end{array}$} \\
\hline Peer pressure & $77 \%$ & Stress & $76 \%$ & Coolness & $76 \%$ & Difficult childhood & $1 \%$ \\
\hline Bad influence & $6 \%$ & Depression & $36 \%$ & Act like an adult & $11 \%$ & & \\
\hline \multirow[t]{8}{*}{ Test of courage } & $4 \%$ & Problems & $36 \%$ & Attention from friends & $3 \%$ & & \\
\hline & & Pleasure & $14 \%$ & Deep voice & $1 \%$ & & \\
\hline & & Appetite suppressant & $9 \%$ & To attract the girls & $1 \%$ & & \\
\hline & & Boredom & $6 \%$ & & & & \\
\hline & & Taste & $4 \%$ & & & & \\
\hline & & Headache & $1 \%$ & & & & \\
\hline & & Stimulation & $1 \%$ & & & & \\
\hline & & Desire to die & $1 \%$ & & & & \\
\hline \multicolumn{2}{|c|}{ Marketing, media } & \multicolumn{2}{|c|}{$\begin{array}{l}\text { Personality traits and temperamental } \\
\text { characteristic }\end{array}$} & \multicolumn{2}{|l|}{ Role modelling } & \multicolumn{2}{|l|}{ Others } \\
\hline \multirow[t]{4}{*}{ Fashion } & $3 \%$ & Curiosity & $46 \%$ & Parents who smoke & $39 \%$ & Addiction & $11 \%$ \\
\hline & & Experimentation & $11 \%$ & Role model & $37 \%$ & Nicotine & $3 \%$ \\
\hline & & Desire & $4 \%$ & Friends who smoke & $34 \%$ & Habit & $1 \%$ \\
\hline & & Allure of danger & $3 \%$ & Passive smoking & $1 \%$ & $\begin{array}{l}\text { Unaware of } \\
\text { consequences }\end{array}$ & $1 \%$ \\
\hline
\end{tabular}

population. This is concerning, because adolescents are unaware of their role and are therefore more vulnerable.

\section{Program acceptance and knowledge gain}

The smoking prevention programme Nichtrauchen ist clever! at the University Hospital Basel was a valuable event and a good source of new information. The three core parts were well accepted by the students, demonstrated by the good to excellent overall ratings. Here, the patient interview was the best-rated part of the programme. Furthermore, Nichtrauchen ist clever! was a good source of new information, which is fundamental for well-informed decision-making.

\section{Future intention 'not to smoke'}

After visiting NIC!, $89 \%$ of the participants expressed their will 'not to smoke in the future'. The importance of volition processes has already been studied in health behaviours such as seat belt use, dietary behaviour, dental flossing and physical activity, ${ }^{35}$ as well as in relation to smoking. ${ }^{36}$ Volitional processes are important for effective behavioural changes and maintenances of health behaviours. Although the cross-sectional study design does not allow any outcome measures, we consider the volition of the adolescents as encouraging.

Our results showed a connection between age and personal experience with tobacco products and the intention 'not to smoke' in the future. In addition, we saw a difference in the evaluation of the different parts of the NIC! programme and in the knowledge gain reported between participants who decided not to smoke in the future and those who were still undecided. The implication of this for the establishment of primary prevention programmes remains unclear. However, it is known that adolescents who are already experimenting with tobacco products or are regular smokers require further measures in order to achieve abstinence from smoking. ${ }^{37}$

\section{Students view on factors influencing smoking initiation}

Our study has shown that students are aware of various factors that influence smoking initiation. There has been an increased awareness of factors such as peer pressure, stress and coolness, which were mentioned in more than two-thirds of all events. A study performed in 2009 by O'Loughlin et al quantifying the impact of different predictors of smoking initiation in adolescents showed that some parameters, such as smoking friends, feeling a need to smoke, susceptibility to cigarette advertisement, alcohol use and use of other tobacco products, were relevant factors on smoking initiation. ${ }^{23}$ We found that students participating in our programme were largely unaware of some of these relevant factors, for example, susceptibility to cigarette advertising. Stress and depression, as part of the predefined intrinsic factors, were among the top listed factors that the students mentioned when assessing the reasons for initiating smoking. As shown by Holliday and Gould, stress has been identified as a risk factor for the decision to start smoking in adolescents. They also showed that stress in adolescents 


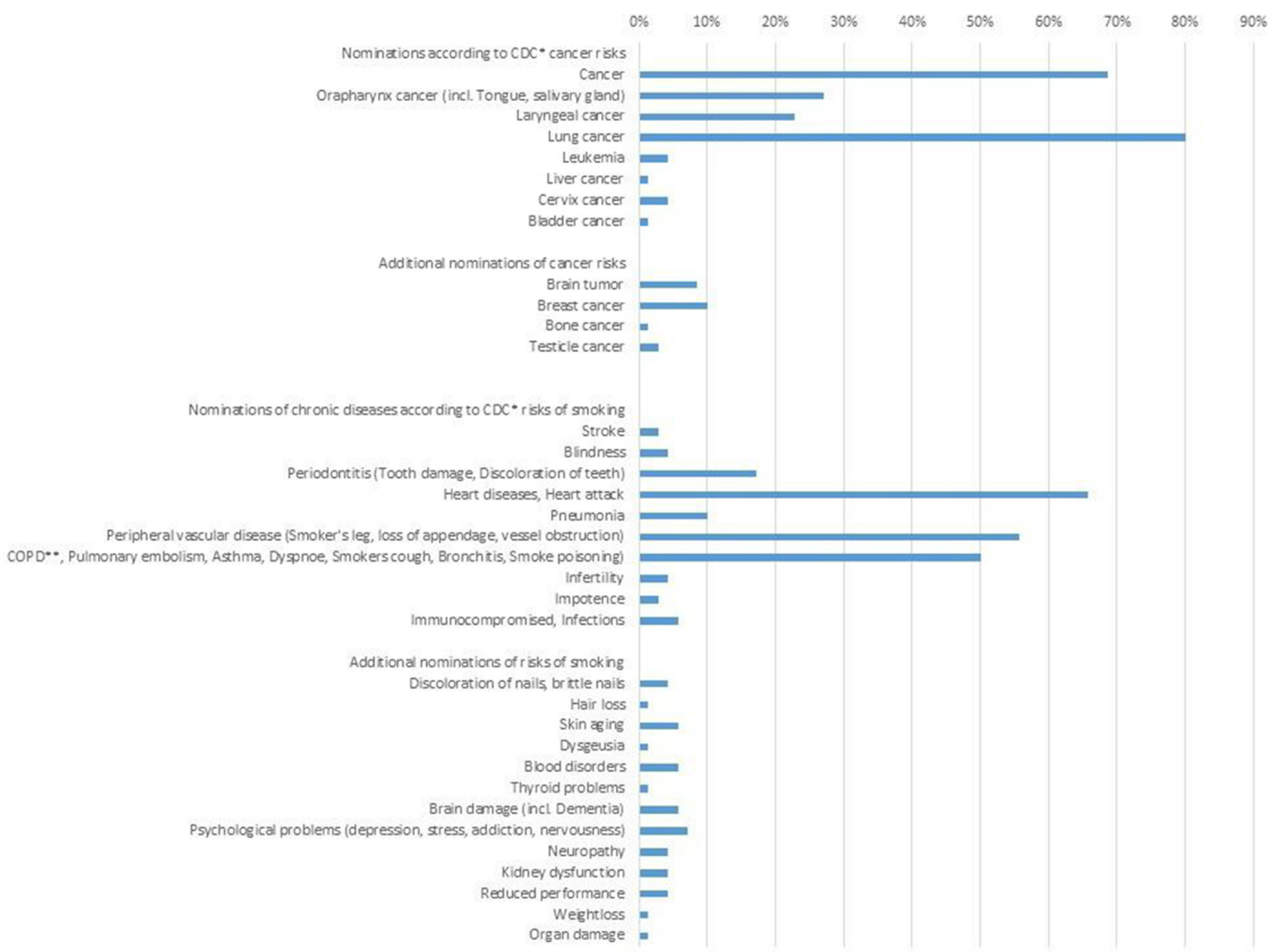

Figure 5 Nomination and frequency (\%) of the various codes for smoking-related diseases brought up in the 70 prevention events. Codes were grouped in cancer risks and chronic diseases (according to the Center for Disease Control and Prevention $\left(\mathrm{CDC}^{*}\right)$ infographic ${ }^{25}$ ) when possible, and additional nominations of cancer risks and additional nomination of risks of smoking when not matching any predefined category. When applicable, each code was encoded at most once per event; however, nomination of different codes per event was possible. COPD** Chronic Obstructive Pulmonary Disease

can enhance the rewarding effect of nicotine. ${ }^{38}$ However, whether stress reduction in adolescents also has a positive effect as an intervention regarding tobacco consumption remains to be investigated.

Remarkably, the vast majority of student-reported factors that can influence the onset of smoking were negative topics such as stress, peer pressure, depression and other issues. Although described in the literature (Talip $e t$ $a l$ 'Some see smoking as fun. ${ }^{21}$ ), we have not predefined a category for purely positive topics such as fun, pleasure or taste. These positive issues as an influencing factor for starting smoking were rarely mentioned in our collective.

Our data show a lack of awareness of the influence of tobacco advertising ${ }^{24} 39$ and tobacco use in movies ${ }^{4}$ on smoking behaviour in adolescents. Furthermore, participants were not aware of the potential influence of socioeconomic and lifestyle-related factors on smoking initiation. Detecting this knowledge gap is particular important, as we can use the prevention programme to close this knowledge gap and therefore raise the awareness on these special and omnipresent risk factors.

\section{Student's perception on smoking-related diseases}

We found that students were aware of the most frequent smoking-related disease, such as lung cancer. However, the study reveals a major knowledge gap in the wide range of health risks and diseases associated with smoking, including fatal diseases other than lung cancer, as well as non-fatal diseases, which may be associated with a relevant loss of quality of life. Given that knowledge can play an important role in preventing the onset of smoking, ${ }^{40}$ therefore knowledge transfer should be promoted further.

\section{Limitations}

The most important methodological limitation is the observational cross-sectional approach of the study without follow-up. We chose this pragmatic approach to start collecting data during the implementation of the 
programme. By having an easy feedback survey design, we wanted to increase the chance of receiving feedback since this was not mandatory for participation. Additionally, there were concerns that establishing a more complex study design right in the initiation phase of the programme could prevent school classes from participating. Our data rely on a self-reported questionnaire from students. Therefore, there is a risk of false reporting (eg, smoking prevalence and programme evaluation). We have tried to minimise this effect through the anonymity of data collection and on questions where smoking status was involved, by counting missing values as triers.

Since the teachers registered the participating school classes for the prevention event, the current study population does not necessarily include a representative sample of young people. Therefore, a generalisation of our results is not necessarily given.

\section{Conclusion}

The smoking prevention programme Nichtrauchen ist clever! conducted by the University Hospital Basel since 2014 seems to be a good source of information for the participants. The participants show basic knowledge of the most common smoking-related illnesses prior to participation and are aware of some factors that could influence smoking initiation. However, the students do not know the broad spectrum of smoke-related health risks and the influence of marketing and media strategies on smoking initiation and behaviour. A high proportion of participants stated that they had learnt a lot and intended not to smoke in the future. Given the limitations of an observational study, further studies are needed to measure the direct preventive effects of NIC! as a smoking prevention programme, hence to be able to adjust the quality and effectiveness of such a programme.

Acknowledgements We thank the educational team of the program 'ohnekippe' for inviting us to Heidelberg and sharing their ideas. Many thanks to Professor Christoph Kaiser, Dr Peter Grendelmeier and the film crew Ditschgi Gutzwiller and Thomas Haldimann for conceptualizing and setting up our films for the prevention event. We also want to thank all our colleagues from the University Hospital Basel, for supporting our program by participating at the events with their patients. Last but not least many thanks to Nathalie Klaus and Christina Blaschke for their support in data entry.

Contributors AM and TB developed and implemented Nichtrauchen ist clever! at the University Hospital Basel. AM, TB and MM have set up the present study, performed data collection, data evaluation and writing the manuscript. AV and MJZ contributed to data evaluation and writing the manuscript. AM, TB, AV and MJZ contributed to the national distribution of the programme. TB and AM had access to the data. All authors approved the final version of the manuscript (AM guarantor).

Funding Initiation of the program Nichtrauchen ist clever! was financially supported by PFIZER: unrestricted medical grant, Research Pool, Medical Outpatient Department University Hospital Basel, Basel, Switzerland, Gesundheitsdepartement Basel-Stadt, Basel, Switzerland; Kahane Foundation, Switzerland; Fondation sana, Bern, Switzerland; Cardiovascular Research Foundation Basel, Switzerland. Additional funding from the University of Basel's Publication Fund for 'open access'.

Competing interests None declared.

Patient consent for publication Not applicable.

Ethics approval The protocol was approved by the local ethical committee without objection (EKNZ Req-2017-00356).

Provenance and peer review Not commissioned; externally peer reviewed.
Data availability statement All data relevant to the study are included in the article or uploaded as supplementary information.

Supplemental material This content has been supplied by the author(s). It has not been vetted by BMJ Publishing Group Limited (BMJ) and may not have been peer-reviewed. Any opinions or recommendations discussed are solely those of the author(s) and are not endorsed by BMJ. BMJ disclaims all liability and responsibility arising from any reliance placed on the content. Where the content includes any translated material, BMJ does not warrant the accuracy and reliability of the translations (including but not limited to local regulations, clinical guidelines, terminology, drug names and drug dosages), and is not responsible for any error and/or omissions arising from translation and adaptation or otherwise.

Open access This is an open access article distributed in accordance with the Creative Commons Attribution Non Commercial (CC BY-NC 4.0) license, which permits others to distribute, remix, adapt, build upon this work non-commercially, and license their derivative works on different terms, provided the original work is properly cited, appropriate credit is given, any changes made indicated, and the use is non-commercial. See: http://creativecommons.org/licenses/by-nc/4.0/.

ORCID iDs

Andrea Meienberg http://orcid.org/0000-0002-0751-2469

Michael Mayr http://orcid.org/0000-0002-1962-8186

\section{REFERENCES}

1 The Health Consequences of Smoking. 50 years of progress. Atlanta, 2016.

2 Health effects of cigarette smoking. Available: https://www.cdc. gov/tobacco/data_statistics/fact_sheets/health_effects/effects_cig smoking/index.htm [Accessed 15 Sep 2021].

3 MPOWER. WHO report on the global tobacco epidemic, 2013, 2013.

4 Wellman RJ, Sugarman DB, DiFranza JR, et al. The extent to which tobacco marketing and tobacco use in films contribute to children's use of tobacco: a meta-analysis. Arch Pediatr Adolesc Med 2006;160:1285-96.

5 Jha P, Ramasundarahettige C, Landsman V, et al. 21st-century hazards of smoking and benefits of cessation in the United States. N Engl J Med 2013;368:341-50.

6 American cancer society, Inc. and vital strategies, 2018. Available: www.tobaccoatlas.org

7 Schweiz S. Suchtmonitoring Schweiz, Konsum von Alkohol, Tabak und illegalen Drogen in Der Schweiz Im Jahr 2012, 2013.

8 Substanzkonsum bei Schülerinnen und Schülern in Der Schweiz Im Jahr 2014 und trend seit 1986 (Forschungsbericht NR. 75). Lausanne 2015.

9 Tabakbedingte Todesfälle in Der Schweiz 1995 bis 20122015.

10 Salloum RG, Thrasher JF, Kates FR, et al. Water pipe tobacco smoking in the United States: findings from the National adult tobacco survey. Prev Med 2015;71:88-93.

11 Westling E, Rusby JC, Crowley R, et al. Electronic cigarette use by youth: prevalence, correlates, and use trajectories from middle to high school. J Adolesc Health 2017;60:660-666.

12 Corongiu S, Dessì C, Cadoni C. Adolescence versus adulthood: differences in basal mesolimbic and nigrostriatal dopamine transmission and response to drugs of abuse. Addict Biol 2020;25:e12721.

13 Scragg R, Wellman RJ, Laugesen M, et al. Diminished autonomy over tobacco can appear with the first cigarettes. Addict Behav 2008;33:689-98.

14 DiFranza JR. A 2015 update on the natural history and diagnosis of nicotine addiction. Curr Pediatr Rev 2015;11:43-55.

15 Baden-Württemberg SL. Mikrozensus Baden-Würtemberg 2005 und 2009: Erwerbstätigkeit, Wohnungswesen, Wahlen, 2009.

16 Qualitative Inhaltsanalyse. Forum Qualitative Sozialforschung 2000.

17 Team RC. R: a language and environment for statistical computing. Vienna, Austria: R foundation for statistical computing; 2019, 2019.

18 Chan SSC, Leung DYP, Abdullah ASM, et al. A randomized controlled trial of a smoking reduction plus nicotine replacement therapy intervention for smokers not willing to quit smoking. Addiction 2011;106:1155-63.

19 Bolliger CT, Zellweger JP, Danielsson T, et al. Smoking reduction with oral nicotine inhalers: double blind, randomised clinical trial of efficacy and safety. BMJ 2000;321:329-33.

20 Wellman RJ, Dugas EN, Dutczak H, et al. Predictors of the onset of cigarette smoking: a systematic review of longitudinal populationbased studies in youth. Am J Prev Med 2016;51:767-78. 
21 Talip T, Kifli N, Murang Z, et al. Smoking initiation and continuation a qualitative study among Bruneian male adolescents. Asian Pac J Cancer Prev 2016;17:3533-40.

22 Sussman S, Dent CW, Mestel-Rauch J, et al. Adolescent nonsmokers, triers, and regular smokers' estimates of cigarette smoking prevalence. When do overestimations occur and by whom? $J$ Appl Soc Psychol 1988;18:537-51.

23 O'Loughlin J, Karp I, Koulis T, et al. Determinants of first puff and daily cigarette smoking in adolescents. Am J Epidemiol 2009;170:585-97.

24 Hanewinkel R, Isensee B, Sargent JD, et al. Cigarette advertising and teen smoking initiation. Pediatrics 2011;127:e271-8.

25 Risks from smoking, 2018. Available: https://www.cdc.gov/ tobacco/infographics/health-effects/pdfs/he-infographic1.pdf? s cid=bb-osh-effects-graphic-005" title="Risks From Smoking: Smoking Can Damage Every Part of the Body. [Accessed 27 Mar 2018].

26 Miech R, Johnston L, O'Malley PM, et al. Trends in adolescent Vaping, 2017-2019. N Engl J Med 2019;381:1490-1.

27 Gentzke AS, Creamer M, Cullen KA, et al. Vital signs: tobacco product use among middle and high school students - United States, 2011-2018. MMWR Morb Mortal Wkly Rep 2019;68:157-64.

28 Treur JL, Rozema AD, Mathijssen JJP, et al. E-cigarette and waterpipe use in two adolescent cohorts: cross-sectional and longitudinal associations with conventional cigarette smoking. Eur J Epidemiol 2018;33:323-34.

29 Soneji S, Barrington-Trimis JL, Wills TA, et al. Association between initial use of e-cigarettes and subsequent cigarette smoking among adolescents and young adults: a systematic review and metaanalysis. JAMA Pediatr 2017;171:788-97.

30 East K, Hitchman SC, Bakolis I. The association between smoking and electronic cigarette use in a cohort of young people. J Adolesc Health 2018
31 Morgenstern M, Nies A, Goecke M, et al. E-Cigarettes and the use of conventional cigarettes. Dtsch Arztebl Int 2018;115:243-8.

32 Owotomo O, Stritzel H, McCabe SE, et al. Smoking intention and progression from e-cigarette use to cigarette smoking. Pediatrics 2020;146. doi:10.1542/peds.2020-002881. [Epub ahead of print: 09 $112020]$.

33 Choi K, Fabian L, Mottey N, et al. Young adults' favorable perceptions of snus, dissolvable tobacco products, and electronic cigarettes: findings from a focus group study. Am J Public Health 2012;102:2088-93.

$34 \mathrm{Xu} \mathrm{X}$, Chen C, Abdullah AS, et al. Knowledge about and sources of smoking-related knowledge, and influencing factors among male urban secondary school students in Chongqing, China. Springerplus 2016;5:1879.

35 Schwarzer R, Schuz B, Ziegelmann JP, et al. Adoption and maintenance of four health behaviors: theory-guided longitudinal studies on dental flossing, seat belt use, dietary behavior, and physical activity. Ann Behav Med 2007;33:156-66.

36 Scholz U, Nagy G, Göhner W, et al. Changes in self-regulatory cognitions as predictors of changes in smoking and nutrition behaviour. Psychol Health 2009;24:545-61.

37 Chun EM. Smoking cessation strategies targeting specific populations. Tuberc Respir Dis 2019;82:1-5.

38 Holliday E, Gould TJ. Nicotine, adolescence, and stress: a review of how stress can modulate the negative consequences of adolescent nicotine abuse. Neurosci Biobehav Rev 2016;65:173-84.

39 Lovato C, Watts A, Stead LF. Impact of tobacco advertising and promotion on increasing adolescent smoking behaviours. Cochrane Database Syst Rev 2011;10:CD003439.

40 Karimy M, Niknami S, Heidarnia AR, et al. Prevalence and determinants of male adolescents' smoking in Iran: an explanation based on the theory of planned behavior. Iran Red Crescent Med J 2013;15:187-93. 